\title{
Memorial lecture in honour of Dr Ailie Key
}

Christa Meyer Dip. O.T., OTR, Lecturer; Department of Occupational Therapy, Medical University of Southern Africa

(This paper is an abbreviated version of the Ailie Key Memorial Lecture given at the first Spinal Cord Injury Congress, in September, 1993)

It is indeed a privilege and an honour to present to you this memorial lecture on Dr Ailie Key who died in December 1992. To all of us who knew her, who worked with her, who were colleagues and who were her friends it is a great loss.

Ailie was the pioneer in the field of rehabilitation of spinal cord injured persons in South Africa and there is no better opportunity to honour her than at this the first spinal cord injury congress ever to be held in South Africa. Ailie Key was a founder member of the Spinal Injury Unit at Conradie hospital together with Dr Mitty Retief in 1963. She was in charge of the Unit from 1971 to 1985 . It was her ambition to provide the best care and rehabilitation for persons with spinal injury so that they would continue life where they had left off before the accident. ${ }^{1}$

The unit at Conradie Hospital became internationally known for its outstandingly successful rehabilitation team and its programme. Professionals from everywhere in the world came to the Conradie Hospital to learn and to gain experience.

In spite of all the fame she remained humble and down to earth. The patient was always her first concern as well as the wellbeing of her team. As a leader she was a continuous source of encouragement and support. She valued her staff's opinions, recognised their contributions and acknowledged peoples abilities and achievements. She challenged one by her untiring efforts to do better.

It was her ambition to assist disabled persons to find their rightful place in society and to integrate back into community life. To this end she served on many committees such as the Association for the Physically Disabled, the Western Cape Council for the Physically Disabled, the Cheshire Homes committee of the Cape of Good Hope and the SA Sports Association for the Disabled.

The biggest loss we have suffered with Ailie Key's death is the loss of a leader in the rehabilitation of the spinal cord injured persons as she practised it at the Conradie Hospital. Because of her able leadership the spinal unit increased from 65 beds to 215 beds. She attracted experts in the field of Medicine, Occupational Therapy and Physiotherapy to work at the Conradie Hospital.

She presented no less than 20 papers at national and international conferences on the topic of management of the spinal cord injured and published several papers in 'Paraplegia' and the South Africa Medical Journal. In 1974 Ailie was elected onto the council of the International Medical Society of Paraplegia and from 1984 to 1987 was the Vice-President of IMSOP.

This Ailie Key memorial lecture focuses on aspects of community involvement and is titled:

\section{Community based rehabilitation - the future for the spinal cord injured in South Africa}

Let us look for a moment at the past and the present before we look at the future.

The past (the 1960's, '70s and mid '80s)

During this time there existed four spinal units including the Conradie Hospital in Cape Town which was established in 1963 by Dr Mitty Retief and Ailie Key.

This time was marked by mainly conservative treatment and long hospitalisation. It was also a time of learning the best treatment methods and establishing rehabilitation programmes. It was a very dynamic time of researching and developing specialised technology such as environmental control units, functional orthoses for tetraplegic patients and the development of the Para-Care cushion at the Conradie Hospital just to name a few. It was a period of time where everyone wanted to go the extra mile and was enthusiastic to spend holidays in order to follow-up discharged patients. People took time to carry out thorough rehabilitation, assisted by the fact that hospital care was less expensive.

\section{The present}

Many more spinal wards and units and rehabilitation facilities have been developed.

The last few years have been marked by many changes particularly in the state hospitals. Changes such as short hospitalisation, surgical intervention intended to speed up rehabilitation; low budgets for equipment and facilities and in many instances, incomplete rehabilitation due to unaffordable hospitalisation, have made comprehensive rehabilitation difficult. This has resulted in many re-admissions with complications such as pressure sores and urinary tract infections. 
Therefore many initiatives are taking place at present in order to find alternative solutions to care and community hospitals have become an essential source for referral and follow-up. Hence the importance of a conference such as this to again create an awareness for the necessity of specialised service in this field of rehabilitation.

Similarly, the establishment of a spinal interest group in the Johannesburg-Pretoria area is a very important development and was initiated by young therapists working in this field to share ideas and experience and to form a support group.

\section{The future}

The future is going to be marked by even more changes than the present. Future focus for rehabilitation is without doubt going to be in the community. Hence I deemed it fit to focus this talk on 'Community Based Rehabilitation', better known as $\mathrm{CBR}$, as a challenge for the future.

The World Health Organisation some 20 years ago, saw this as a possible solution to cope with the $10 \%$ of disabled persons in the world. CBR is the only way in which we can provide rehabilitation for all in the future South Africa.

\section{Community based rehabilitation}

Dr Einar Helander ${ }^{2}$ from the WHO defines Community Based Rehabilitation as a 'strategy for improving service delivery, for providing more equitable opportunities and for promoting and protecting the human rights of disabled people'. It calls for the full and coordinated involvement of all levels of society: community, intermediate and national. It seeks the integration of the interventions of all relevant sectorseducational, health, legislative, social and vocationaland aims at the full representation and empowerment of disabled people. It also aims at promoting such interventions in the general systems of society, as well as adaptations of the environment that will facilitate their social integration and their self-actualization. Its goal is to bring about a change; to develop a system capable of reaching all disabled people in need and to educate and involve governments and the public, using in each country a level of resources that is realistic and maintainable.

The CBR strategy is a learning process not a blueprint or a ready-made solution. It takes into consideration the current social, cultural and economic situation, the situation of disabled people, the country's existing services and personnel, phases of development as well as the country's own priorities and policies.

Pamela Haynes ${ }^{3}$ describes the objective of Community-Based Rehabilitation as 'the social integration or, more specifically, the active participation of disabled people in the mainstream of community life. It involves measures taken at the community level to use and build on the resources of the community, including the impaired, the disabled, and the handicapped people themselves'.

Dr Laura Krefting ${ }^{4}$ a CBR Consultant, in a paper presented in July 1993 at the national congress of the South African Association of Occupational Therapists in Pretoria, describes three services:

(a) Community outreach

(b) Community centred and

(c) Community focused services.

The community outreach service is client centred. The Community centred service is client and family centred while the third involves the community at large with issues such as disability prevention campaigns, attempting to influence existing infrastructure, managing disability issues, advocating the rights of the disabled and networking with other services such as the Disabled People South Africa (DPSA), and the Community Rehabilitation Workers (CRW).

\section{Available human resources}

The extent of disablement in the community is extensive and the area of rehabilitation has been neglected particularly so in the rural community and thus calls us to change the focus to the need of disabled persons in rural areas.

Pam Haynes ${ }^{3}$ outlined the situation in respect of rehabilitation posts and personnel, highlighted the lack of rehabilitation facilities and the scarcity of therapists in outlying areas of South Africa. In the then existing homelands with a population of 12 million and a surface area of some 171 thousand square kilometers there were only 104 hospitals and a total of 33,000 beds. The rehabilitation structure was as follows: 116 Physiotherapy posts, 64 Occupational Therapy posts and three Speech and hearing therapy posts. Only 40 Physio, 23 OT and one Speech and hearing therapy posts were filled at the time. This gave a therapist population ratio of $1: 295,000$ for Physiotherapy and 1:513,000 for Occupational Therapy. See Table 1 .

We need to ask ourselves who is going to do the work in the community if we have such a shortage of

\section{Table 1}

Human resources in rural areas (1987)

Population

Number of Hospitals

Number of Beds

Number of Physiotherapy posts

Number of Occupational Therapy posts

Number of Speech \& Hearing Therapy posts

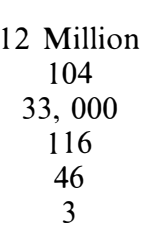

Therapist: Population ratio (Employed at the time: 1987) Physiotherapy $1: 300,000$ Occupational Therapy

Speech \& Hearing Therapist 
professionals and where is the rehabilitation going to take place if there are so few facilities? From the above mentioned statistics it is no one else than the members of the community themselves. That in essence calls for empowering the disabled persons and in turn empowering the community to assist in rehabilitation. Disabled people need to recognise that they can contribute to rehabiliation services in the community. The role of the professionals then needs to change from that of a manager of a rehabilitation service to that of a resource person on whom the community members can call whenever required.

The CBR worker ( $C R W$ )

This is a person from the community trained specifically for his/her community. The CRW is a trained person whose task it is to identify the needs of the disabled, identify local resources available for intervention, facilitate intervention, make appropriate referrals, educate and train the family and friends of the disabled person where necessary, promote community development, and develop support programmes. Whenever necessary referrals are made for expert advice and consultation with professionals. The CRW is a vital member of the community health team.

The CRWs in South Africa do a 2 year training and several courses are offered in different parts of the country. Through the service of the CRW we would alleviate the extensive shortage of rehabilitation personnel in the neglected community.

\section{Community development}

One of the essential aspects the CBR programme needs to focus on is community development. The people of the community should be involved in the planning and implementation of rehabilitation programmes. Loren$\mathrm{zo}^{5}$ stresses the importance that the people are encouraged to identify what they feel their need is by way of a question such as "what is it that you would like me to do for you? The focus is on the person and his need and not on superimposed ideas and perceptions of people from outside the community. This in turn encourages ownership and sustainability of community programmes.

For this to happen, everyone involved needs to learn to listen. By listening to the needs of the community a strong attitude of self-determination and self-reliance is fostered. A sense of dignity is built up as the community members discover that within themselves they have a great power to make progress and to make a contribution to the welfare of others in their community.

An attitude of learning and serving needs to be adopted by health workers. We need to work with the people and teach them skills to become self sufficient and in this way help them to break out of the dependency role of disability and resume responsibility for their own needs.
This now brings me back to Ailie Key whom we are remembering today and whom we are honouring for the contribution she made in this country towards rehabilitation of the spinal cord injured persons. Was this not what she was actually aiming for with rehabilitation at the Conradie Hospital and was that not empowering the disabled? It was her ambition that the spinal injured person be rehabilitated to his maximum level of independence so as to take up his rightful place again whether it be at work, in the family or society at large with skills he was taught in hospital be they those of self help and personal independence, work or social interaction. The purpose was that they were empowered to live a life of quality and a meaningful life.

We only need to look at some of her 'protoges' amongst the spinal cord injured who are now leading professionals in their own right. They are able leaders in the disability movement in South Africa, empowered to contribute to the upliftment of the community because of Ailie's influence.

I take the liberty to say that Ailie Key already had this vision of CBR without giving it a name or having identified it as such. If we look at the titles of some of her publications such as 'social integration of paraplegics and tetraplegics in the Cape Province of the RSA' or 'Home Industries - a realistic rehabilitation programme for the spinal cord injured from a developing country', there is no doubt in my mind that this was what she saw as a realistic and meaningful goal for rehabilitation.

There is nothing better we can do to honour Ailie Key than to follow her example with courage, conviction and commitment.

\section{Conclusion}

Do we have a vision for the future rehabilitation of the spinal cord injured person? Do we believe that we can make a difference in spite of all the emanating changes in our country? I believe we can. But we need to be flexible, imaginative and creative in our thinking to meet the challenges with optimism.

In closing I would like to quote Susan Hammersmith, ${ }^{6}$ the Secretary General of Rehabilitation International, who wrote:

'It has been said of rehabilitation that we have pioneered many miracles for a few. The challenge we face to-day is to accomplish a few miracles for the many'.

Let's identify the 'few miracles' to bring about rehabilitation for the many spinal cord injured persons in the future South Africa.

\section{Acknowledgements}

I wish to thank Estelle Shipham for her encouragement and assistance in preparing this lecture and also Yvonne van Schalkwyk for the final typing of the paper. 


\section{References}

1 Key AG et al. Social Reintegration of Paraplegics and Tetraplegics in the Cape Province of the Republic of South Africa. Paraplegia 1982; 20: $103-107$.

2 Helander E. UNDP Geneva. A Description of Community Based Rehabilitation. Rl Pre-Congress Seminar Procedures, Limuru, Kenya, August 31-September 3, 1992. p. 52.

3 Haynes P. How can Occupational Therapy in South Africa contribute to the attainment of Rehabilitation for All. SAJOT, May 1991, 2(1) pp.6-17.
4 Krefting L. Community - the essence of Occupational Therapy. Paper presented at the SAAOT Congress, Pretoria, July 1993.

5 Lorenzo T. The Challenges of a Community Based Rehabilitation Programme in a Rural Area in Gazankulu. SAJOT, May 1991 21(1). pp. $18-22$

6 Hammerman S. As quoted by P McLaren in SAJOT, May 1991 21(1). pp. $6-17$ 